\title{
Comparative spatial inequality dynamics: The case of Mexico and the United States
}

\author{
Sergio J. ReY ${ }^{1} \quad$ Myrna L. Sastré Gutiérrez ${ }^{2}$
}

January 5, 2015

${ }^{1}$ GeoDa Center for Geospatial Analysis and Computation, School of Geographical Sciences and Urban Planning, Arizona State University, srey@asu.edu. Rey's research was supported in part by National Science Foundation Grant SES-1421935.

${ }^{2}$ Universidad Autónoma de Coahuila, Architecture Department, Urban Studies myrna.sastre@uadec.edu.mx, myrna.sastre@gmail.com. 
Comparative spatial inequality dynamics: The case of Mexico and the United States 


\begin{abstract}
In this paper we examine the trajectory of regional income inequality dynamics for two neighboring national systems. Using data on 3,038 US counties and 2,418 Mexico municipios, from 2000, 2005, and 2010, we employ recent extensions of spatial Markov chains and space-time mobility measures, to consider the following questions: Are regional inequality dynamics fundamentally distinct between Mexico and the United States? Does the role of spatial context influence the distributional dynamics of the two systems? Finally we examine if there is a distinct bi-national border international border region that displays inequality dynamics different from those of the internal regions of the two national systems. Strong evidence of spatial heterogeneity in regional income mobility is found between the two national systems, with Mexico having higher mobility relative to the US. The international border region is found to have distinct mobility dynamics from either national system, experiencing the strongest mobility. Extensive evidence of spatial contextual effects are found throughout the US-Mexican pooled data set indicating that a region's transitional dynamics are influenced by incomes of neighboring regions.
\end{abstract}

Key Words: Spatial Markov, regional convergence, spatial effects, US-Mexico 


\section{Introduction}

The debate about changes of interpersonal and interregional inequality has been active for at least a fifty year span (Kuznets, 1955; Hughes, 1961; Williamson, 1965; Amos Jr, 1988; Krebs, 1982). Following the difficulties in empirically contrasting the main premise, namely, that inequality will tend to decrease with development levels, and erratic evidence about the mechanisms for this latter to hold, interest has continued in two broad directions. A theoretical perspective has revived the discussion on the relationship between growth and inequality (Aghion and Williamson, 1998; Quah, 2003), while a regional view has focused on the enduring nature of regional inequality in some areas (Kanbur and Zhang, 2005; Fan and Casetti, 1994) and the effects of more recent global dynamics on regional disparities (Silva and Leichenko, 2004; Krugman and Venables, 1995; Dobson and Ramlogan, 2009). In regional studies, the question continues to be linked mostly to structural development levels and regional differentiation (Venables, 2005; Wan et al., 2007; Zhang and Zhang, 2003; Kanbur and Venables, 2005; Scott and Storper, 2007; Costa, 2011 ), and there is a renewed interest in policy related questions addressing the regional issue (Fan et al., 2009; Wei, 2002).

With the theoretical recognition of accompanying contextual effects, particularly in regional growth processes (Krugman, 1990, 1997, 1999), but also in interaction-based approaches in social dynamics (Blume and Durlauf, 2001), the interest has also turned to spatio-temporal inquiries around these issues ( $\mathrm{Li}$ and Wei, 2010; Fan and Casetti, 1994). Within this recent dynamic perspective, studies concerned with regional inequality have found in parametric approaches a new set of testable hypothesis reflecting temporal disequilibrium. The use of regressions of regional growth on initial levels of income has been extensive in testing the probability of catching up or, so called, regional convergence (Barro and Sala-i-Martin, 1992). Despite its attachment to formal growth theories and thus, well defined transition dynamics, the approach has proven to be limited to the investigation of many of the previous questions, involving dynamics in subsets of economies that are likely to differ over space. This has been accompanied by new growth theories which have a particular attachment to mechanisms that are geographically localized (Aghion et al., 1998). On the empirical front, evidence of weaknesses within the convergence framework, among them, the presence of rigidities (as opposite to mobility) in transition dynamics has been frequently revealed, challenging explanations of transient distributional characteristics predicted by a neoclassical approach.

These latter shortcomings have motivated the emergence of a relatively new thread in the literature referred to as a distributional dynamics approach to convergence (Durlauf et al., 2005). From an initial focus on a measure of dispersion, so called $\sigma$-convergence, the empirical approach has greatly evolved over the last two decades. Within this framework, a particular interest in spatial processes as intervening dynamics was first visible in a critique to traditional approaches (Quah, 1993b), followed by revised empirics (Quah, 1996b) which seek to integrate the relevance of contextual effects. This methodological focus was further developed with measures where spatial relationships, and dynamics involved, are more fully captured (Rey, 2001, 2004b). This has allowed the identification of a new range of intra-distribution dynamics which are sensitive to the spatial context (Rey, 2001). This has also posed new questions on the relationship between space and regional 
inequality (Rey, 2004a; Novotnỳ, 2007; Rey and Sastré-Gutiérrez, 2010) and convergence (Wei and Ye, 2009; Rey and Janikas, 2005).

In this paper we seek to contribute to the distributional dynamics literature by adopting a comparative perspective. To do so we examine the trajectory of regional income inequality dynamics for two neighboring national systems, the United States and Mexico. Employing recent extensions of spatial Markov chains and space-time mobility measures in distributional dynamics (Rey, 2001, 2004b), we consider the following questions:

- Are regional inequality dynamics fundamentally distinct between Mexico and the United States?

- What role does spatial context play in shaping the distributional dynamics of the two national systems?

- Is the bi-national international border region a third system that displays distinct inequality dynamics from those of the internal regions of the two countries?

The remainder of the paper is organized as follows. In Section 2 we provide an overview of the regional context for our work. The empirical strategy, data sources and analytical methods are discussed in Section 3. The results of our analysis are then presented in Section 4, and the paper concludes with a summary of key findings and discussion of directions for future research.

\section{Background}

\subsection{Comparative Mexico and US regional dynamics}

The rich history between Mexico and the US can be traced over a number of of periods. One of them involves several interconnected events back to the colonial past in Mexico and civil wars in both countries. Another encompasses a more contemporary set of events, relating to adjustments to global dynamics, such as opening processes and regional restructuring. Structural (and historical) aspects are fundamental when discussing factors shaping regional differences in living standards in both countries. In Mexico, the focus has been mainly on a north-south divide (Alba, 1999; López-Alonso, 2007; De Appendini et al., 1972; Hernández Laos, 1984). The northern states that share a border with the U.S. have displayed higher performance relative to the southern states. Herzog (1990)[p.4], refers to the national economic development program conducted in Mexico during the second half of the twentieth century as, "...directed at expanding, economically fortifying, and physically redeveloping cities lying on the northern frontier." In the US, on the other hand, states transitioned through a concentration of economic activities in the Northeast and Midwest that started during the nineteen century, followed by what has been termed a polarization reversal (Fan and Casetti, 1994) that resulted in new cores of activities in the South and West. A similar effect occurs in Mexico a couple of decades later, as strong evidence also points to a shift of the core of the economic activity from the center of Mexico to the northern part of the country, initiated with the unilateral opening process during the mid 1980s and intensified after the North American Free Trade Agreement (NAFTA). 
Since the NAFTA between the United States, Canada and Mexico was put into force in 1994, the question of intranational income dynamics has attracted substantial attention. This has had several motivations stemming from remarks by influential international trade theories regarding regional impacts through opening processes (Krugman and Venables, 1995), and mixed evidence drawn from regional processes operating in Mexico. On one side are findings about a reversion of income convergence among the Mexican states, which is frequently linked with the aftermath of liberalization reforms in the country (Chiquiar, 2005; Messmacher, 2000; Sánchez-Reaza and Rodríguez-Pose, 2002). Arguably, some of these regional responses also reflect the outstanding conditions of the northern border area of Mexico (Krugman and Hanson, 1993; Venables, 2005). Meanwhile, recent studies refer to regional disequilibrium also on structural or historical grounds (Aroca et al., 2005; Rey and Sastré-Gutiérrez, 2010). These studies point to a strong north-south gradient -prior to NAFTA- influencing overall regional divergence (Aroca et al., 2005), with the genesis of such pattern to be found in uneven regional distributive policies during the 1940s.

On the other hand, many of these previous studies have suggested a range of potential interdependencies operating between regional systems, Mexico and the United States, across various spatial socioeconomic dimensions and scales. These latter notions are largely descriptive and are still lacking an a formal analytical treatment and associated inferential framework. In other words, these ideas have not been conclusive about the extent and nature of those forces (if existent), their strength and relative importance.

From the standpoint of spatial statistics, several aspects remain to unexamined. We are uncertain to what extent significant spatial effects are present in the area, and how they may affect spatial dynamics in the rest of the regional systems (if such bi-national spatial regimes do, in fact, exist). For example, would the spatial dynamics of some of the Mexican northern states change if we metaphorically modify their neighborhood from having US states to having Mexican states as neighbors? Nor do we know if the probabilities of poor US counties improving their income are affected by having poor (or rich) municipios as neighbors in the Mexican side of the border. We also wonder how spatial dynamics in the hinterlands of both countries, might change if, for instance, their vicinity with the other country was removed. Identifying local spatial dynamics could help to set up useful benchmarks to add to studies that implicitly have posed these questions.

\section{$2.2 \quad$ A regional border system?}

The recent spatial turn in many fields is rapidly contributing to the emergence of research questions which increasingly have a composite nature (Pries, 2005; Jessop et al., 2008). As stated by sociologists, the study of spatial inequality has the advantage of broadening our knowledge of social inequality (economic well-being, access to resources, class, etc.) to more fully understanding of uneven development (Lobao et al., 2007a). This same strand of the literature has increasingly recognized the usefulness of scale analysis as a mean to establish spatial arrangements and connections (Lobao et al., 2008, 2007b). In this view, the territories of interest are wide ranging and include regions, states, counties, i.e., a variety of spatial scales, which are "...geographic levels at which social processes work themselves out" (Lobao et al., 2007a, p.3). Clearly put, with these scalar studies, we are able to recognize descriptive variations, but more importantly, "...identify how and why 
the spatial context contributes to inequality" (Lobao et al., 2007a, p.3). In this particular, border areas have generated fascinating discussions.

The debate around the relevance of borders in recent years has opened several lines of inquiry (Krugman, 2004; Newman, 2006; Niebuhr, 2006; Niebuhr and Stiller, 2002). For example, anthropological positions assess the symbolism of borders and political and social implications of their porousness. As recognized by ethnographers, on the discussion of borderlands "The varying strengths with which people subscribe to a particular national identity, and its uneven spread across a state's domain, may thus be illuminated by the knowledge of border dynamics" (Wilson and Donnan, 1998, p. 16). The influential theoretical wave, new economic geography (Krugman, 1999), assigns an important role to spatial processes taking place along formal or informal boundaries, reflected in agglomerations at various spatial scales, the economics of this question being the forces determining the location of economic activities. Regional border scholars are interested in integration effects, which from the standpoint of economic development studies, also concerns the potential outcomes in terms of regional imbalance (Anderson and O'dowd, 1999; Ohr, 1995).

One of the most complex borderlines in the world, due (among other things) to its extension (1,954 mi) and human activity (350 million crossings per year), is the US-Mexico area. ${ }^{1}$ In addition to their geographical disposition, relevant dynamics took place during the second half of the past century on both sides of the border area. In the U.S., relevant changes in political and economic geography occurred, with the development of, so called, Sunbelt states and related settlements in towns along the Mexican border (Herzog, 1990). On the Mexican side, these latter dynamics were coupled with reinforcing regional policies towards the northern area. Furthermore, the implications of these dynamics for regional development imbalance have been informed by historians. From this perspective, both, the superior performance of the northern border region and more generally, the unequal wealth distribution in the country, can be traced back to post-revolutionary (1920-), and industrialization (1934-40) periods. Recent evidence implicitly points to the intensification of spatial interaction as the area became strategic for the US-Mexico trade relationship from 1994 and thereafter.

These concerns have led to increased interest about the dynamics taking place in the Mexico-US border area, which is considered a repository for social, economic, and political relationships (Herzog, 1990). Its complexity has made the area an interesting subject of study for several disciplines. A range of questions have attracted the attention of scholars, from regional integration and development asymmetries to interregional dynamics vs. intranational response relative to national environments (Mendoza Cota, 2006; Anderson and Gerber, 2004; Alegría, 1989). For instance, with an urban, sociological focus, Alegría (1989) analyses the effect of dependency brought by the geographic adjacency to the border on both sides of the international Mexico-US border, pointing out that "in the establishment of inter-urban hierarchies in border regions, Mexican cities show a greater dependence than do their US counterparts on the fact that they are located on the border." This suggests that regional effects (relative to national effects on those same areas) are greater for Mexican cities than they are for US localities.

\footnotetext{
${ }^{1}$ Border crossing figures come from the International Boundary and Water Commission.
} 
Very frequently, narratives in geographical, philosophical, economic, demographic and political studies, refer to the border area of Mexico and the United States as a region (Lorey and Buj, 1991; Mollá Ruiz-Gómez, 2011; Pick et al., 2002). More recently, some studies have recognized the lack of agreement about this definition, pointing out to difficulties to accurately define the territorial extension of the area, suggesting that a more proper one should be attached to the subject under study (Ordónez, 2013). According to the definition given by SEMARNAT (1983), the border zone is located up to 100 kilometers in both sides of the territorial and maritime dividing lines between the two countries. On the Mexican side, this zone include 80 municipios and 6 border states (Ordóñez, 2013, p.91). Given the degree of heterogeneity at the municipio scale, apparently linked to their urban or rural conditions, some studies still find this regional definition inaccurate (Ordóñez, 2013; Graizbord and Hiernaux, 1982).

\section{Methods}

Given the wide ranging nature of the theoretical, historical and policy literature surrounding regional development dynamics in the US and Mexico, we feel it is important to adopt a formal empirical strategy that draws on recent developments in spatial distribution dynamics. In this way we hope to contribute empirical insights to the broader discussions. Here we describe our methodological strategy and data sources that are employed.

\subsection{Data}

For Mexico, we use annual per capita income series at municipal level (in PPP international dollars of 2010), comparable for years 2000, 2005 and 2010. The data was drawn from the United Nations Development Program (UNDP) in Mexico. ${ }^{2}$ Three main sources are used to construct comparable per capita income series at the municipal level: the National Survey of Income and Expenditure of Households (Encuesta Nacional de Ingresos y Gastos de los Hogares (ENIGH); the Censo General de Población y Vivienda; and Conteo de Población y Vivienda, all of them conducted by the Instituto Nacional de Estadística, Geografía e Informática (INEGI), the agency in charge of statistical information in Mexico. The estimated (average) per capita income per municipio is adjusted through a conversion factor in terms of purchasing power parity in U.S. dollars. ${ }^{3}$

For the US per capita income data is obtained from the U.S. Department of Commerce, Bureau of Economic Analysis, Regional Economic Accounts series and set to constant 2010 dollars. The combined data set has 5,546 spatial units, 2,418 municipios in Mexico and 3,038 counties in the US. ${ }^{4}$

Figure 1 displays the spatial distribution of per capita incomes, in U.S. dollars, for the pooled data using a quintile classification. A general north-south pattern can be seen both

\footnotetext{
${ }^{2}$ http://www.undp.org.mx. We thank this organization for the valuable help offered in clarifying information for us during the data preparation.

3 "Purchasing power parity conversion factor is the number of units of a country's currency required to buy the same amounts of goods and services in the domestic market as U.S. dollar would buy in the United States." http://data.worldbank.org/indicator/PA.NUS.PPP

${ }^{4}$ For the US only the 48-lower US states are used and the District of Columbia is excluded.
} 


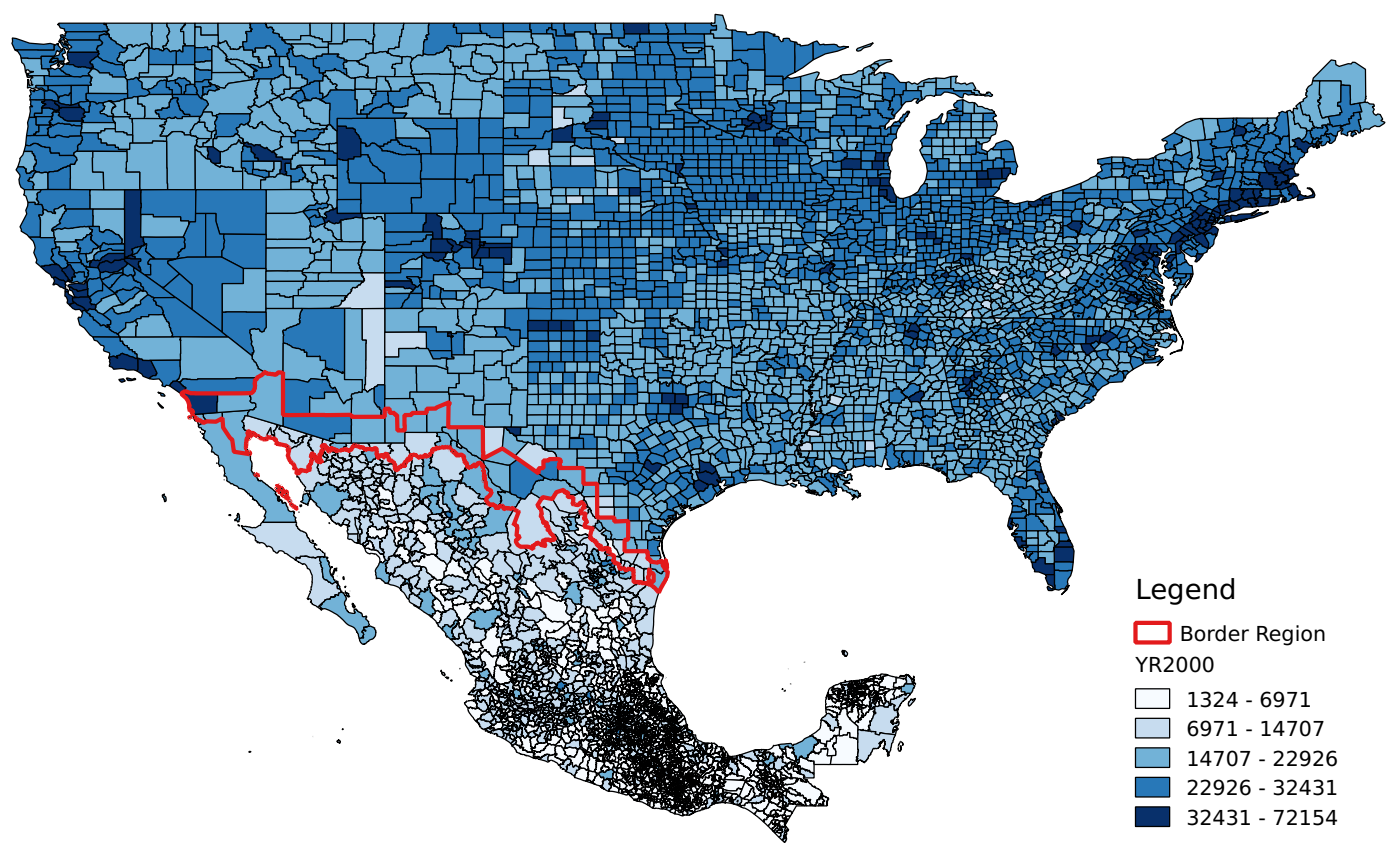

Figure 1: Per capita incomes US counties and Mexican Municipios 2000 (Quintiles, U.S. $\$)$

for the bi-national system as a whole, as well as operating within each country individually. Also shown is the international border region which reaches into both national systems.

\subsection{Income Distribution Dynamics}

The approach originally suggested by Quah (1993a, 1996b), simultaneously challenged traditional, temporal and spatial notions of convergence empirics. A first approximation to the temporal question was devoted to highlight shortcomings in a neoclassic approach to the empirics of income convergence, which are considered to place unrealistic assumptions on transition dynamics in order to interpret limiting distributions. Quah proposed a shift in focus to give more importance to the dynamics involved in the evolution of income distributions, and thus, to a new empirical framework that were more in touch with these questions. The new empirics were revealing of the other major pillar in this perspective, namely, the importance of contextual factors for distributional processes (Quah, 1996c,a). This finding was in clear contrast with predictions from mainstream growth theories, and more in line with new theoretical paradigms of regional growth with endogenous and cumulative processes involved. Apart from the convergence debate, this shift in focus 
provoked more interest to be directed to income distributional inequality.

A distributional approach to investigate income distribution dynamics, considers both growth and distribution jointly (Quah, 2001). Two broad classes of distributional dynamics have been suggested. The first one derives from the examination of statistical and theoretical properties of the Markov chain framework and specific modeling restrictions under the approach (Fingleton, 1997; Bickenbach and Bode, 2003). Methodologically, these questions have been frequently assessed, among other, through examination of the formal model, in establishing distinctions and scope relative to parametric approaches and available tests statistics in considerable technical detail. A second strand in this literature centers on spatial considerations within the approach the Markov framework (Rey et al., 2011; Rey, 2014b,c). In this case, the search of robust ways to introduce spatial dynamics has become a key component for both, analytical and empirical approaches to growth and distribution.

\subsubsection{Morphology}

A central aspect of distributional dynamics is the change in the overall morphology of the income distribution. Several approaches towards studying this evolution have been suggested in the literature. Most common is the notion of a stochastic kernel which can be viewed as a conditional distribution function that maps incomes in period $y_{t}$ into those in the next period $y_{t+1}$. At the same time, marginal distributions for the distribution at a given point in time can be derived from the kernel. The evolution of these marginal densities overtime can then be examined for changes in their morphology that may suggest polarization, bi-modality, skewness, dispersion or compression.

\subsubsection{Markov chains}

As a counter part to the continuous approach of the stochastic kernel, discrete-state Markov chains have been widely adopted in the study of regional convergence and inequality dynamics. Such a chain is a a stochastic process $\left\{y_{t}\right\}$ defined by a $k$-dimensional state space, in our context, income per capita classes $c_{k, t} .{ }^{5}$ Empirically, this scheme requires the specification of the value for $k$ as well as the boundaries that form the classes $0 \leqslant c_{1, t} \leqslant c_{2, t} \leqslant \ldots c_{k, t}$. The probability distribution evolves according to the following law of motion (Rey, 2004a; Fingleton, 1997):

$$
\pi_{t+1}=\pi_{t} P
$$

where $\pi_{t+1}$ is a $1 \times k$ row vector, whose $i$ th element is the proportion of the regions in income class $i$ in period $t+1$, and $P$ is a $k \times k$ probability transition matrix with elements $p_{i, j}$ specifying the conditional probability that given a region begins a period in class $i$ it will transition to class $j$.

\section{Space-time properties}

\footnotetext{
${ }^{5}$ The terms class and state are used interchangeably to refer to a position within the transition probability matrix.
} 
If the transition probabilities are stationary over time, then through recursion it follows that $\pi_{t+q}=\pi_{t} P^{q}$. The distribution is called stationary or time invariant if it satisfies, $\pi_{s+1}=\pi_{s}$, for some period $s$ after which the conditional distribution remains the same with the passage of time. ${ }^{6}$ Whether a given empirical regional time series is consistent with a stationary distribution is an important question. In order to preserve the space - time Markov properties of a chain, careful consideration of this property should also be given to these aspects in space. We come back to this question in what follows.

\subsubsection{Mobility Measures}

The transition probability matrix governs the evolution of the income distribution. As such, summary measures of the amount of mobility in that evolution have been suggested. To compare mobility of different Markov chains in this paper we rely on two such mobility measures. The first was suggested by Shorrocks (1978):

$$
S M I(P)=\frac{k-\sum_{i=1}^{k} p_{i, i}}{k-1}
$$

where $k$ is the number of states in the chain. This is a global measure of mobility in the sense that it averages over the individual states of the chain. As a complement to this global indicator, we also apply the Prais (1955) conditional mobility measures:

$$
\operatorname{PMI}\left(P_{i}\right)=1-p_{i, i}
$$

which reflects mobility conditioned upon the chain being in state $i$ at the beginning of a transition period.

\subsubsection{Spatial Homogeneity}

In the present context, some of these previous concerns reflect in the possibility that specific groups of regions could be governed by different dynamic processes. This could result in misleading conclusions about both the transition probability matrix and limiting distribution if we assume that they originate from the same process (Bickenbach and Bode, 2003). This points to inherent problems, so called, modifiable areal unit problems (MAUP) in the spatial context, in which case, the goal is finding a set of homogeneous regions that display similar distribution dynamics. Feasible solutions will vary with the research question and analytical requirements. For instance, (Magrini, 2007), re-scales the unit of analysis from administrative to functional regions in the search of analytical boundaries to investigate distributional dynamics.

One possible way to assess the Markov properties in a spatial context, proceeds as follows. The whole area $U$ under study is divided into $\mathrm{R}$ mutually exclusive and exhaustive regimes $r(r=1, \ldots, R ; R \leqslant U)$. The probabilities can be estimated via maximum likelihood (ML) approach, i.e. the relative frequencies of observed transitions from $i$ to $j$ over the entire time period for each specific regime:

\footnotetext{
${ }^{6}$ This gives the Markov chain the characteristic of irreducibility, that is, every state in the chain is reachable from every other state, not necessarily in one step. If the returning time to $i$ is finite, then state $i$ is also known as positive recurrent.
} 


$$
\hat{p}_{i j \mid r}=n_{i j \mid r} / n_{i \mid r}
$$

where $n_{i \mid r}$ represents row $i$ of the transition matrix involving regions from regime $r$, $n_{i j \mid r}=\sum_{t} n_{i j \mid r}(t)$, and $n_{i \mid r}=\sum_{t} n_{i \mid r}(t-1)$. The transition probabilities computed for the entire system (i.e., pooled over all regions) are compared to transitions from the regions (regimes), under the null,

$$
H_{0}: p_{i j \mid r}=p_{i j}
$$

in other words, this hypothesizes spatial homogeneity of the dynamics across regimes.

Two tests have been suggested in the literature (Bickenbach and Bode, 2003, p.369):

$$
\begin{aligned}
& L R^{(R)}=2 \sum_{r=1}^{R} \sum_{i=1}^{N} \sum_{j \in A_{i \mid j}} n_{i j \mid r} \ln \frac{\hat{p}_{i j \mid r}}{\hat{p}_{i j}} \sim \operatorname{asy} \chi^{2}\left(\sum_{i=1}^{N}\left(a_{i}-1\right)\left(b_{i}-1\right)\right), \\
& Q^{(R)}=\sum_{r=1}^{R} \sum_{i=1}^{N} \sum_{j \in A_{i}} n_{i \mid r} \frac{\left(\hat{p}_{i j \mid r}-\hat{p}_{i j}\right)}{\hat{p}_{i j}} \sim \operatorname{asy}^{2}\left(\sum_{i=1}^{N}\left(a_{i}-1\right)\left(b_{i}-1\right)\right),
\end{aligned}
$$

where $A_{i \mid r}=\left\{j: \hat{p}_{i j \mid r}>0\right\}$ represents the set of nonzero transition probabilities in the $i$ th row of the transition matrix computed from each regime $r, A_{i}=\left\{j: \hat{p}_{i j}>0\right\}$ is a set of nonzero transition probabilities in the $i$ th row of the transition matrix for the entire sample, $a_{i}$ is the number of elements in $A_{i}$, and $b_{i}$ is the number of regimes for which we have available observations for the $i$ th row $\left(b_{i}=\left\{r: n_{i \mid r}>0\right\}\right)$. The statistics have an asymptotic $\chi^{2}$ distribution with degrees of freedom (DOF) equal to the number of independent pairwise comparisons $(N-1)^{2}$, assuming all transition probabilities to be positive. Otherwise (with zero transition probabilities), degrees of freedom have to be adjusted. In both tests, $L R^{(R)}$ or $Q^{(R)}, H_{0}$ is rejected, as usual, if the statistic exceeds the critical value.

\subsubsection{Spatial Markov transitions dynamics}

A complementary way to explore spatial dependence in transitional dynamics in this context has been developed by Rey (2001, 2004a), in a spatial Markov chain arrangement. Under this framework, the $k \times k$ Markov chain probability transitions matrix $P_{i j}$ is conditioned on the spatial lag (average income) of neighboring regions with states $l(=1, \ldots, L)$, at time $t-1$, to give $p_{i j \mid l}$. This allows to deal with otherwise intractable spatial dependence in this context. The spatial Markov chain can be viewed as a special case of the more general homogeneity testing framework above. However, here a neighborhood structure, theoretically or empirically informed, must used to control for the degree of interaction allowed within the regimes. The spatial Markov chain approach controls for these questions, by integrating a local spatial structure to identify spatial dependence in transition dynamics.

In this study, the specification of class boundaries $c_{k, t}$ adopts a local quantile function, based on the cumulative distribution function $F_{y_{t}}$ which in our context allows for the 


\begin{tabular}{rrrr|rrr}
\hline & \multicolumn{3}{c|}{ Mexico } & \multicolumn{3}{c}{ US } \\
& 2000 & 2005 & 2010 & 2000 & 2005 & 2010 \\
\hline $\bar{y}$ & 7112.73 & 8224.01 & 8676.98 & 30646.99 & 32670.39 & 34007.37 \\
$y_{\text {med }}$ & 6198.00 & 7224.50 & 7847.00 & 29567.18 & 31381.86 & 32628.00 \\
$y_{\max }$ & 46944.00 & 46369.00 & 47249.00 & 105936.23 & 111749.83 & 111122.00 \\
$y_{\min }$ & 1324.00 & 2011.00 & 2405.00 & 13021.53 & 15366.66 & 15924.00 \\
$\sigma_{y}$ & 4324.30 & 4158.90 & 4212.37 & 7540.97 & 7717.22 & 7821.07 \\
$100 * \sigma_{y} / \bar{y}$ & 60.80 & 50.57 & 48.55 & 24.61 & 23.62 & 23.00 \\
\hline
\end{tabular}

Table 1: Summary statistics for US County and Mexican Municipio income distributions.

investigation of income exchange mobility occurring within the quintile classes. The class boundaries are obtained from (Rey, 2014a):

$$
c_{i, t}=Q\left(\frac{i}{k}\right)\{i: 1,2, \ldots, k\}
$$

with the possibility of $c_{i, t} \neq c_{i, t+l}$. As before, these dynamically conditioned spatial transition matrices could be used to test independence in spatial dynamics across segmented income classes using (6) and (7) across those segments.

\section{Results}

\subsection{Density Morphology Dynamics}

Figure 2 reports the densities estimated for the pooled US-Mexico system in each of the three years. The bi-modality of the densities are readily apparent in each of the three years, suggesting that the two national systems are distinct. At the same time, the two peaks display a rightward shift over time, suggesting a general improvement in the average income in both Mexican municipios and US counties. By contrast, Figure 3 displays the kernel density functions for each national system and year of our study. Several key distinctions between the two national systems emerge. There is a clear differentiation in the locations of the two sets of densities with the center of the Mexican distributions falling to the left of the US densities.

A second clear pattern is the more peaked nature of the Mexican densities relative to the US distributions. However, if one compares this visual representation of concentration with numerical measures of dispersion, it is clear that the Mexican distributions are characterized by greater relative dispersion. Table 1 reports summary measures for the densities, including the coefficient of variation which is higher each year for Mexico relative to the US. Both systems do experience a similar decline in dispersion over time.

\subsection{National Mobility Patterns}

We turn to the question of the internal dynamics of the distributions drawing on Markov chain based methods. Our first question is whether the mobility dynamics are distinct 


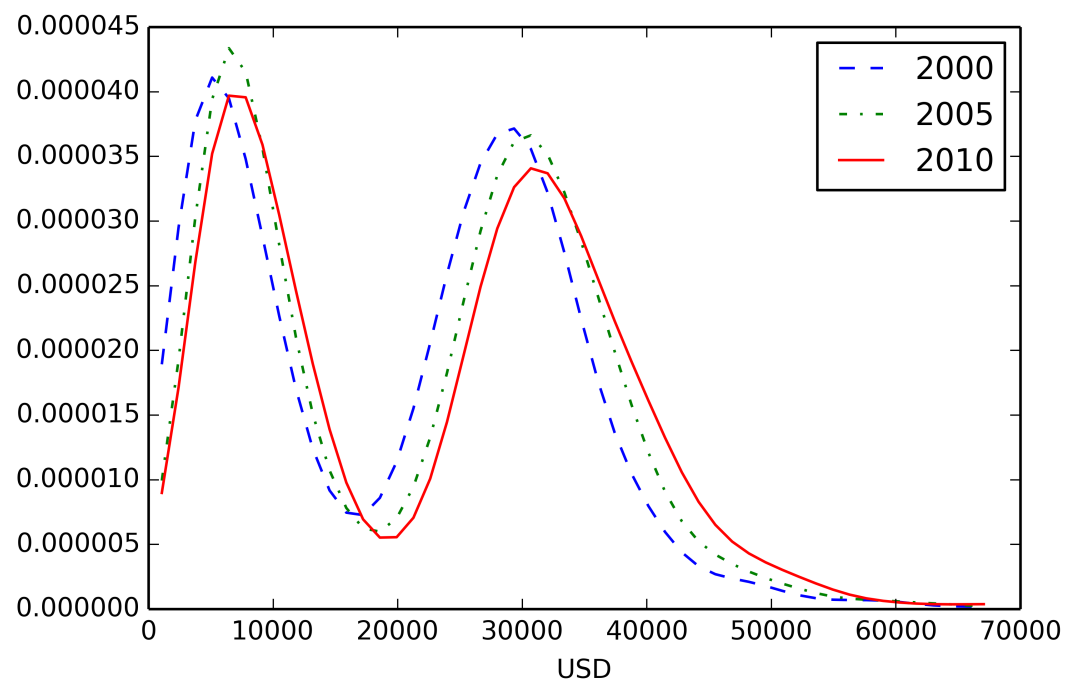

Figure 2: Pooled US County and Mexico Municipio Income Densities, 2000, 2005, 2010



Figure 3: US County and Mexico Municipio Income Densities, 2000, 2005, 2010 
between the Mexican and US systems. To examine this we first pool the income data from each system for a given year and form the quantiles on the integrated series. Using the quantiles we then estimate the transition probabilities for a discrete five-state Markov chain. The estimated transition probability matrix for the pooled system is reported in the third panel of Table 2 .

We then test whether the chain is homogeneous across the two systems by estimating separate transition probability matrices using country-specific subsets of the pooled quantiles. These matrices are reported in the fourth and fifth panels of Table 2 for Mexico and the US, respectively. There is strong evidence that the dynamics are not homogeneous between the two national systems as both the likelihood ratio (LR) and $\chi^{2}$ tests are significant.

Comparison of the estimated transition probability matrix for the pooled series $P(H 0)$ with the two estimates for the individual systems $P(M e x)$ and $P(U S)$ reveals the source of the heterogeneity as the lower quintiles are dominated by Mexican transitions - indeed the incomes of the poorest counties in the US all exceed the first quantile in the pooled series. Moreover, there is only a single US transition that began in quartile 2 during the sample. Conversely, the pooled transition probabilities in the upper quartiles are dominated by US transitions.

Given that the homogeneity assumption can be rejected when using absolute quantiles, the question arises as to whether the relative dynamics are distinct between the two countries. More specifically, if the states of the Markov chains are defined using the quintiles specific to each country, rather than the pooled series, does the heterogeneity in the dynamics remain?

This question is examined in Table 3. Again there is clear evidence that the internal distribution dynamics are different between the two countries as both tests remain significant even after relaxing the definition of the quintiles to be country specific.

A closer examination of Tables 2 and 3 reveals several findings that further differentiate the US and Mexican space economies. Recall from the previous discussion that the homogeneity tests in (6) and (7) have their degrees of freedom corrected for the number of zero cells in the pooled matrices and or rows in the marginal matrices lacking any non-zero cells. By defining the quintiles on the pooled system the class boundaries are stretched out to the extent that the number of zero cells in the transition matrices increases. This is reflected in the smaller degrees of freedom in Table 2 compared to Table 3.

Table 4 reports summary mobility measures for the two systems based on the countryspecific (relative) quantiles. The Prais conditional mobility indices $(P 1-P 5)$ for Mexico are greater than those for the US across all quintiles. The global mobility measure (Shorrock) is also higher for Mexico relative to the US.

Taking the results of Tables 2-4 together it is clear that the neighboring countries have distinct spatial mobility dynamics as the municipios within Mexico display greater movement within the national-space income distribution than that experienced by US counties. 


\begin{tabular}{|c|c|c|c|c|c|}
\hline \multicolumn{6}{|c|}{ Markov Homogeneity Test } \\
\hline \multirow{4}{*}{\multicolumn{6}{|c|}{$\begin{array}{l}\text { Number of classes: } 5 \\
\text { Number of transitions: } 10912 \\
\text { Number of regimes: } 2 \\
\text { Regime names: Mex, US }\end{array}$}} \\
\hline & & & & & \\
\hline & & & & & \\
\hline & & & & & \\
\hline \multicolumn{2}{|c|}{ Test } & \multicolumn{2}{|c|}{ LR } & \multicolumn{2}{|r|}{$Q$} \\
\hline \multicolumn{2}{|l|}{ Stat. } & \multicolumn{2}{|c|}{785.835} & \multicolumn{2}{|c|}{1754.852} \\
\hline \multicolumn{2}{|l|}{ DOF } & \multicolumn{2}{|r|}{13} & \multicolumn{2}{|c|}{13} \\
\hline \multicolumn{2}{|l|}{ p-value } & \multicolumn{2}{|r|}{0.000} & \multicolumn{2}{|r|}{0.000} \\
\hline $\mathrm{P}(\mathrm{H} 0)$ & 0 & 1 & 2 & 3 & 4 \\
\hline 0 & 0.806 & 0.194 & 0.000 & 0.000 & 0.000 \\
\hline 1 & 0.192 & 0.732 & 0.075 & 0.000 & 0.000 \\
\hline 2 & 0.002 & 0.072 & 0.784 & 0.131 & 0.011 \\
\hline 3 & 0.000 & 0.001 & 0.136 & 0.711 & 0.152 \\
\hline 4 & 0.000 & 0.000 & 0.005 & 0.158 & 0.837 \\
\hline $\mathrm{P}(\mathrm{Mex})$ & 0 & 1 & 2 & 3 & 4 \\
\hline 0 & 0.806 & 0.194 & 0.000 & 0.000 & 0.000 \\
\hline 1 & 0.193 & 0.734 & 0.073 & 0.000 & 0.000 \\
\hline 2 & 0.011 & 0.359 & 0.616 & 0.011 & 0.002 \\
\hline 3 & 0.000 & 0.091 & 0.727 & 0.091 & 0.091 \\
\hline 4 & 0.000 & 0.071 & 0.286 & 0.357 & 0.286 \\
\hline $\mathrm{P}(\mathrm{US})$ & 0 & 1 & 2 & 3 & 4 \\
\hline 0 & 0.000 & 0.000 & 0.000 & 0.000 & 0.000 \\
\hline 1 & 0.000 & 0.143 & 0.714 & 0.143 & 0.000 \\
\hline 2 & 0.000 & 0.000 & 0.826 & 0.161 & 0.013 \\
\hline 3 & 0.000 & 0.000 & 0.130 & 0.717 & 0.153 \\
\hline 4 & 0.000 & 0.000 & 0.003 & 0.156 & 0.841 \\
\hline
\end{tabular}

Table 2: Pooled Quantile Markov Homogeneity Tests, Mexico Municipios vs. US Counties 


\begin{tabular}{|c|c|c|c|c|c|}
\hline \multicolumn{6}{|c|}{ Markov Homogeneity Test } \\
\hline \multicolumn{6}{|c|}{$\begin{array}{l}\text { Number of classes: } 5 \\
\text { Number of transitions: } 10912 \\
\text { Number of regimes: } 2 \\
\text { Regime names: Mex, US }\end{array}$} \\
\hline Test & & & LR & & Q \\
\hline Stat. & & & 03.081 & & 93.013 \\
\hline $\mathrm{DOF}$ & & & 20 & & 20 \\
\hline p-value & & & 0.000 & & 0.000 \\
\hline $\mathrm{P}(\mathrm{H} 0)$ & 0 & 1 & 2 & 3 & 4 \\
\hline 0 & 0.738 & 0.211 & 0.036 & 0.011 & 0.004 \\
\hline 1 & 0.217 & 0.485 & 0.233 & 0.059 & 0.007 \\
\hline 2 & 0.038 & 0.253 & 0.454 & 0.220 & 0.036 \\
\hline 3 & 0.006 & 0.045 & 0.244 & 0.497 & 0.208 \\
\hline 4 & 0.002 & 0.006 & 0.033 & 0.213 & 0.747 \\
\hline $\mathrm{P}(\mathrm{Mex})$ & 0 & 1 & 2 & 3 & 4 \\
\hline 0 & 0.686 & 0.243 & 0.057 & 0.013 & 0.001 \\
\hline 1 & 0.236 & 0.404 & 0.269 & 0.082 & 0.009 \\
\hline 2 & 0.065 & 0.260 & 0.380 & 0.250 & 0.044 \\
\hline 3 & 0.012 & 0.080 & 0.234 & 0.435 & 0.239 \\
\hline 4 & 0.002 & 0.013 & 0.059 & 0.219 & 0.707 \\
\hline $\mathrm{P}(\mathrm{US})$ & 0 & 1 & 2 & 3 & 4 \\
\hline 0 & 0.779 & 0.186 & 0.020 & 0.010 & 0.006 \\
\hline 1 & 0.201 & 0.549 & 0.204 & 0.040 & 0.005 \\
\hline 2 & 0.016 & 0.246 & 0.513 & 0.195 & 0.029 \\
\hline 3 & 0.002 & 0.018 & 0.252 & 0.546 & 0.183 \\
\hline 4 & 0.002 & 0.000 & 0.012 & 0.208 & 0.779 \\
\hline
\end{tabular}

Table 3: Relative Quantile Markov Homogeneity Tests, Mexico Municipios vs. US Counties

\begin{tabular}{lrrrrr|r}
\hline Country & P1 & P2 & P3 & P4 & P5 & Shorrock \\
\hline Mex. & 0.314 & 0.596 & 0.619 & 0.565 & 0.293 & 0.597 \\
US & 0.221 & 0.451 & 0.487 & 0.454 & 0.214 & 0.459 \\
\hline
\end{tabular}

Table 4: Summary mobility measures - US and Mexico relative quantile transition probability matrices. $P 1-P 5$ are the Prais conditional mobility indices: $P J=\sum_{i \neq J} p_{J, i}$. 


\subsection{International Border Dynamics}

While the US and Mexican systems clearly display different income mobility dynamics, a related question is whether the bi-national border region itself is distinct from either national system. To address this we partition the observations into three groups: US internal (i.e., non-border) counties; Mexico internal municipios; and the 23 US counties and 37 Mexico municipios that define the international border region. Table 5 carries out the homogeneity test for the transitional dynamics across these three groups. Clearly the homogeneity assumption is rejected. This is not surprising given that the sample is numerically dominated by the internal economies of both systems and the finding above that the US and Mexico systems are clearly distinct in their mobility dynamics.

To refine the question, we next carry out a homogeneity test of the US internal counties versus the international border region, and then repeat the test for the case of Mexico internal municipios and the border region. Tables 6 and 7 report the results of these tests for the US vs. Border and Mexico vs. Border cases, respectively. Homogeneity is rejected in both cases. Close examination of the two tables reveals that mobility is always higher across the quantiles in the border region than is the case for the US, while the same holds for most quintiles in the Mexico case. Only in the second and fifth quintiles is mobility greater for internal Mexico than the international border, which could suggest local (or income segments) explanations to the mobility differences between the two countries reported previously.

\subsection{Spatial Dynamics}

The homogeneity tests above indicate some evidence of spatial heterogeneity in the sense that the mobility dynamics are revealed to be different across the US, border and Mexican systems. At the same time, those tests assume that the transitions that an economy makes in its income distribution is independent of the level of income in surrounding regions. To explore this, we next carry out a test of the Spatial Markov framework, described in section 3.1. Table 8 has the results from applying the test to the pooled county and municipio series using year specific quintiles, where the quintiles are defined on the pooled system.

There is strong evidence that the regional context can affect the transition dynamics. For example, economies in the first quintile at the beginning of a period have a 0.806 probability of remaining there in the next period on average. However, if an economy is in the first quintile, but is surrounded by economies with an average income in the first quintile that probability increases to 0.822 . At the other end of the distribution, an economy in the fifth quintile at the beginning of a transition period has a 0.837 probability of remaining there on average, yet economies in the fifth quintile surrounded by economies also in that quintile see this probability increase to 0.860 . The two formal homogeneity tests reject the null that the transitional dynamics are uniform across the five classes of the spatial lag. ${ }^{7}$

The spatial Markov analysis in this section, shows clear distinctions in the way in

\footnotetext{
${ }^{7}$ Since the spatial Markov chain requires a large number of observations for estimation of the conditional transition probabilities, the small number of units on the international border preclude a comparison of the spatial dynamics there against the two systems.
} 


\begin{tabular}{|c|c|c|c|c|c|}
\hline \multicolumn{6}{|c|}{ Markov Homogeneity Test } \\
\hline \multirow{4}{*}{\multicolumn{6}{|c|}{$\begin{array}{l}\text { Number of classes: } 5 \\
\text { Number of transitions: } 10912 \\
\text { Number of regimes: } 3 \\
\text { Regime names: USNB, MEXNB, BORDER }\end{array}$}} \\
\hline & & & & & \\
\hline & & & & & \\
\hline & & & & & \\
\hline Test & & & LR & & Q \\
\hline Stat. & & & 61.967 & & 381.646 \\
\hline DOF & & & 40 & & 40 \\
\hline p-value & & & 0.000 & & 0.000 \\
\hline $\mathrm{P}(\mathrm{H} 0)$ & Q1 & Q2 & Q3 & Q4 & Q5 \\
\hline Q1 & 0.734 & 0.213 & 0.038 & 0.012 & 0.004 \\
\hline Q2 & 0.216 & 0.480 & 0.238 & 0.059 & 0.007 \\
\hline Q3 & 0.041 & 0.252 & 0.451 & 0.219 & 0.038 \\
\hline Q4 & 0.007 & 0.048 & 0.243 & 0.491 & 0.211 \\
\hline Q5 & 0.003 & 0.006 & 0.031 & 0.219 & 0.741 \\
\hline$\overline{\mathrm{P}(\mathrm{USNB})}$ & Q1 & Q2 & Q3 & Q4 & Q5 \\
\hline Q1 & 0.778 & 0.187 & 0.020 & 0.010 & 0.006 \\
\hline Q2 & 0.203 & 0.545 & 0.208 & 0.039 & 0.005 \\
\hline Q3 & 0.016 & 0.250 & 0.509 & 0.196 & 0.029 \\
\hline Q4 & 0.002 & 0.018 & 0.251 & 0.547 & 0.182 \\
\hline Q5 & 0.002 & 0.000 & 0.012 & 0.208 & 0.779 \\
\hline $\mathrm{P}(\mathrm{MEXNB})$ & Q1 & Q2 & Q3 & Q4 & Q5 \\
\hline Q1 & 0.683 & 0.243 & 0.058 & 0.015 & 0.001 \\
\hline Q2 & 0.234 & 0.400 & 0.272 & 0.084 & 0.009 \\
\hline Q3 & 0.068 & 0.258 & 0.380 & 0.244 & 0.049 \\
\hline Q4 & 0.012 & 0.084 & 0.237 & 0.422 & 0.246 \\
\hline Q5 & 0.003 & 0.014 & 0.054 & 0.235 & 0.694 \\
\hline $\mathrm{P}(\mathrm{BORDER})$ & Q1 & Q2 & Q3 & Q4 & Q5 \\
\hline Q1 & 0.542 & 0.333 & 0.125 & 0.000 & 0.000 \\
\hline Q2 & 0.125 & 0.417 & 0.375 & 0.083 & 0.000 \\
\hline Q3 & 0.208 & 0.083 & 0.333 & 0.375 & 0.000 \\
\hline Q4 & 0.083 & 0.125 & 0.083 & 0.417 & 0.292 \\
\hline Q5 & 0.042 & 0.042 & 0.083 & 0.125 & 0.708 \\
\hline
\end{tabular}

Table 5: Relative Quantile Markov Homogeneity Tests, Internal US Counties, Internal Mexico Municipios vs. Binational Border Counties and Municipios 


\begin{tabular}{|c|c|c|c|c|c|}
\hline \multicolumn{6}{|c|}{ Markov Homogeneity Test } \\
\hline \multirow{4}{*}{\multicolumn{6}{|c|}{$\begin{array}{l}\text { Number of classes: } 5 \\
\text { Number of transitions: } 6150 \\
\text { Number of regimes: } 2 \\
\text { Regime names: USNB, BORDER }\end{array}$}} \\
\hline & & & & & \\
\hline & & & & & \\
\hline & & & & & \\
\hline \multicolumn{3}{|l|}{ Test } & LR & \multicolumn{2}{|r|}{ Q } \\
\hline Stat. & & & 80.412 & & 218.082 \\
\hline DOF & & & 20 & & 20 \\
\hline $\mathrm{p}$-value & & & 0.000 & & 0.000 \\
\hline$\overline{\mathrm{P}(\mathrm{H} 0)}$ & Q1 & Q2 & Q3 & $\mathrm{Q} 4$ & Q5 \\
\hline Q1 & 0.773 & 0.189 & 0.022 & 0.010 & 0.006 \\
\hline Q2 & 0.202 & 0.542 & 0.211 & 0.040 & 0.005 \\
\hline Q3 & 0.020 & 0.247 & 0.506 & 0.199 & 0.028 \\
\hline Q4 & 0.003 & 0.020 & 0.248 & 0.545 & 0.184 \\
\hline Q5 & 0.002 & 0.001 & 0.013 & 0.207 & 0.777 \\
\hline $\mathrm{P}(\mathrm{USNB})$ & Q1 & Q2 & Q3 & $\mathrm{Q} 4$ & Q5 \\
\hline Q1 & 0.778 & 0.187 & 0.020 & 0.010 & 0.006 \\
\hline Q2 & 0.203 & 0.545 & 0.208 & 0.039 & 0.005 \\
\hline Q3 & 0.016 & 0.250 & 0.509 & 0.196 & 0.029 \\
\hline Q4 & 0.002 & 0.018 & 0.251 & 0.547 & 0.182 \\
\hline Q5 & 0.002 & 0.000 & 0.012 & 0.208 & 0.779 \\
\hline $\mathrm{P}(\mathrm{BORDER})$ & Q1 & Q2 & Q3 & Q4 & Q5 \\
\hline Q1 & 0.542 & 0.333 & 0.125 & 0.000 & 0.000 \\
\hline Q2 & 0.125 & 0.417 & 0.375 & 0.083 & 0.000 \\
\hline Q3 & 0.208 & 0.083 & 0.333 & 0.375 & 0.000 \\
\hline Q4 & 0.083 & 0.125 & 0.083 & 0.417 & 0.292 \\
\hline Q5 & 0.042 & 0.042 & 0.083 & 0.125 & 0.708 \\
\hline
\end{tabular}

Table 6: Relative Quantile Markov Homogeneity Tests, Internal US Counties vs. Binational Border Counties and Municipios 


\begin{tabular}{|c|c|c|c|c|c|}
\hline \multicolumn{6}{|c|}{ Markov Homogeneity Test } \\
\hline \multirow{4}{*}{\multicolumn{6}{|c|}{$\begin{array}{l}\text { Number of classes: } 5 \\
\text { Number of transitions: } 4882 \\
\text { Number of regimes: } 2 \\
\text { Regime names: MEXNB, BORDER }\end{array}$}} \\
\hline & & & & & \\
\hline & & & & & \\
\hline & & & & & \\
\hline Test & & & LR & & Q \\
\hline Stat. & & & 31.851 & & 41.578 \\
\hline DOF & & & 20 & & 20 \\
\hline p-value & & & 0.045 & & 0.003 \\
\hline $\mathrm{P}(\mathrm{H} 0)$ & Q1 & Q2 & Q3 & Q4 & Q5 \\
\hline Q1 & 0.680 & 0.245 & 0.059 & 0.014 & 0.001 \\
\hline Q2 & 0.232 & 0.401 & 0.275 & 0.084 & 0.009 \\
\hline Q3 & 0.072 & 0.254 & 0.379 & 0.248 & 0.048 \\
\hline Q4 & 0.013 & 0.085 & 0.233 & 0.422 & 0.247 \\
\hline Q5 & 0.004 & 0.014 & 0.054 & 0.233 & 0.695 \\
\hline $\mathrm{P}(\mathrm{MEXNB})$ & Q1 & Q2 & Q3 & Q4 & Q5 \\
\hline Q1 & 0.683 & 0.243 & 0.058 & 0.015 & 0.001 \\
\hline Q2 & 0.234 & 0.400 & 0.272 & 0.084 & 0.009 \\
\hline Q3 & 0.068 & 0.258 & 0.380 & 0.244 & 0.049 \\
\hline Q4 & 0.012 & 0.084 & 0.237 & 0.422 & 0.246 \\
\hline Q5 & 0.003 & 0.014 & 0.054 & 0.235 & 0.694 \\
\hline $\mathrm{P}(\mathrm{BORDER})$ & Q1 & Q2 & Q3 & Q4 & Q5 \\
\hline Q1 & 0.542 & 0.333 & 0.125 & 0.000 & 0.000 \\
\hline $\mathrm{Q} 2$ & 0.125 & 0.417 & 0.375 & 0.083 & 0.000 \\
\hline Q3 & 0.208 & 0.083 & 0.333 & 0.375 & 0.000 \\
\hline Q4 & 0.083 & 0.125 & 0.083 & 0.417 & 0.292 \\
\hline Q5 & 0.042 & 0.042 & 0.083 & 0.125 & 0.708 \\
\hline
\end{tabular}

Table 7: Relative Quantile Markov Homogeneity Tests, Internal Mexico Municipios vs. Binational Border Counties and Municipios 
which differences in the spatial context (i.e. the segmented income classes of neighbors) may be influencing transition dynamics. Previous studies using a similar distributional approach have found significant the influence that these sort of spatial mobility has on distributional outcomes (Sastré-Gutiérrez and Rey, 2013). The more spatially dependent and segmented is income in space, the more rigid seems to be the distribution and more difficult to change over time. In this sense, more mobility will not necessarily translate in distributional spatial change. Overall spatially dependent exchange mobility seem to rule the whole bi-national system and therefore it is likely to be localized. The border region is a good candidate for these localized dynamics. The observed distinct behavior of the border, namely, more distributional mobility, points to relevant cross-boundary effects in the area between the two nations. Nonetheless, the finding of mobility should consider potential interdependencies, i.e. positive or negative spatial income dependence, or other distinctive spatial processes, substantively signaling cohesive, competitive or other behaviors of localities in the area. The findings together, point to the presence of spatially specific income dynamics in the border area and outside the bounded national spaces.

\section{Conclusions}

Several areas of inquiry have been opened due to regional disequilibrium around the world. Empirically, an interesting natural exercise has been the exploration of income dynamics in areas that underwent institutionalized integration while political boundaries remained unchanged (Le Gallo, 2004; López-Bazo et al., 1999; Bosker, 2009). These studies have illuminated the relevance of space in this context, however, conclusions are greatly based on restrictive theoretical assumptions. The investigation of flows and processes across space naturally leads to studies of countries, cities and regions in a comparative fashion, and heavily relies on the technical treatment of such areas under a notion of regional systems (Rey and Janikas, 2006).

In this study, our aim has been to contribute to this literature with a comparative study of a particular bi-national system and, in many respects a unique data set. The United States and Mexico share an intertwined history of conflict, passing through informal intricate geographic conurbations and formal trade agreements. It is precisely this complexity, which highlights the validity of interesting comparisons between the two neighboring systems. As in the case of other comparative studies involving pairs of countries (Maxwell, 1994), with marked differences, the scholarly interest is constantly fueled by several fronts. Moreover, in contrast to most comparative studies, an extensive borderline region, a sort of first and second geographic feature, characterizes this particular bi-national system.

Application of methods of exploratory spatial distribution dynamics reveals a number of key findings. First, we find strong evidence that regional income mobility dynamics are significantly different between the US and Mexican national systems. Higher mobility is found for Mexico relative to the US over the 2000-2010 period. This, coupled with the finding of differences in inequality between the two countries (higher dispersion during the whole period for the Mexican case) could be indicative of country-specific relationships between mobility, inequality and equalization prospects. Second, despite the difference in overall mobility dynamics, the two systems share a common characteristic in that regions 


\begin{tabular}{|c|c|c|c|c|c|}
\hline \multicolumn{6}{|c|}{ Spatial Markov Test Income } \\
\hline \multirow{4}{*}{\multicolumn{6}{|c|}{$\begin{array}{l}\text { Number of classes: } 5 \\
\text { Number of transitions: } 10912 \\
\text { Number of regimes: } 5 \\
\text { Regime names: LAG0, LAG1, LAG2, LAG3, LAG4 }\end{array}$}} \\
\hline & & & & & \\
\hline & & & & & \\
\hline & & & & & \\
\hline \multicolumn{2}{|l|}{ Test } & \multicolumn{2}{|r|}{ LR } & \multicolumn{2}{|r|}{$\mathrm{Q}$} \\
\hline \multicolumn{2}{|l|}{ Stat. } & \multicolumn{2}{|c|}{702.703} & \multicolumn{2}{|r|}{2520.343} \\
\hline \multicolumn{2}{|l|}{$\mathrm{DOF}$} & \multicolumn{2}{|r|}{55} & \multicolumn{2}{|r|}{55} \\
\hline \multicolumn{2}{|l|}{ p-value } & \multicolumn{2}{|r|}{0.000} & \multicolumn{2}{|r|}{0.000} \\
\hline $\mathrm{P}(\mathrm{H} 0)$ & $\mathrm{C} 0$ & C1 & $\mathrm{C} 2$ & C3 & $\mathrm{C} 4$ \\
\hline $\mathrm{C} 0$ & 0.806 & 0.194 & 0.000 & 0.000 & 0.000 \\
\hline $\mathrm{C} 1$ & 0.192 & 0.732 & 0.075 & 0.000 & 0.000 \\
\hline $\mathrm{C} 2$ & 0.002 & 0.072 & 0.784 & 0.131 & 0.011 \\
\hline C3 & 0.000 & 0.001 & 0.136 & 0.711 & 0.152 \\
\hline $\mathrm{C} 4$ & 0.000 & 0.000 & 0.005 & 0.158 & 0.837 \\
\hline $\mathrm{P}(\mathrm{LAG} 0)$ & $\mathrm{C} 0$ & $\mathrm{C} 1$ & $\mathrm{C} 2$ & C3 & $\mathrm{C} 4$ \\
\hline $\mathrm{C} 0$ & 0.822 & 0.178 & 0.000 & 0.000 & 0.000 \\
\hline $\mathrm{C} 1$ & 0.236 & 0.695 & 0.069 & 0.000 & 0.000 \\
\hline $\mathrm{C} 2$ & 0.016 & 0.407 & 0.561 & 0.008 & 0.008 \\
\hline $\mathrm{C} 3$ & 0.000 & 0.000 & 0.667 & 0.167 & 0.167 \\
\hline $\mathrm{C} 4$ & 0.000 & 0.000 & 0.250 & 0.750 & 0.000 \\
\hline $\mathrm{P}(\mathrm{LAG} 1)$ & $\mathrm{C} 0$ & $\mathrm{C} 1$ & $\mathrm{C} 2$ & C3 & $\mathrm{C} 4$ \\
\hline $\mathrm{C} 0$ & 0.792 & 0.206 & 0.001 & 0.000 & 0.000 \\
\hline $\mathrm{C} 1$ & 0.180 & 0.747 & 0.073 & 0.000 & 0.000 \\
\hline $\mathrm{C} 2$ & 0.013 & 0.330 & 0.644 & 0.013 & 0.000 \\
\hline C3 & 0.000 & 0.200 & 0.700 & 0.100 & 0.000 \\
\hline $\mathrm{C} 4$ & 0.000 & 0.000 & 0.333 & 0.333 & 0.333 \\
\hline $\mathrm{P}(\mathrm{LAG} 2)$ & C0 & C1 & $\mathrm{C} 2$ & C3 & $\mathrm{C} 4$ \\
\hline $\mathrm{C} 0$ & 0.699 & 0.301 & 0.000 & 0.000 & 0.000 \\
\hline $\mathrm{C} 1$ & 0.126 & 0.776 & 0.097 & 0.000 & 0.000 \\
\hline $\mathrm{C} 2$ & 0.000 & 0.026 & 0.849 & 0.117 & 0.008 \\
\hline C3 & 0.000 & 0.000 & 0.175 & 0.718 & 0.107 \\
\hline $\mathrm{C} 4$ & 0.000 & 0.008 & 0.008 & 0.210 & 0.774 \\
\hline $\mathrm{P}$ (LAG3) & $\mathrm{CO}$ & $\mathrm{C} 1$ & $\mathrm{C} 2$ & C3 & $\mathrm{C} 4$ \\
\hline $\mathrm{C} 0$ & 1.000 & 0.000 & 0.000 & 0.000 & 0.000 \\
\hline $\mathrm{C} 1$ & 0.000 & 0.000 & 0.500 & 0.500 & 0.000 \\
\hline $\mathrm{C} 2$ & 0.000 & 0.000 & 0.758 & 0.223 & 0.019 \\
\hline C3 & 0.000 & 0.000 & 0.135 & 0.730 & 0.135 \\
\hline $\mathrm{C} 4$ & 0.000 & 0.000 & 0.007 & 0.192 & 0.801 \\
\hline $\mathrm{P}(\mathrm{LAG} 4)$ & $\mathrm{C} 0$ & $\mathrm{C} 1$ & $\mathrm{C} 2$ & C3 & $\mathrm{C} 4$ \\
\hline $\mathrm{C} 0$ & 0.000 & 0.000 & 0.000 & 0.000 & 0.000 \\
\hline $\mathrm{C} 1$ & 0.000 & 0.000 & 0.000 & 0.000 & 0.000 \\
\hline $\mathrm{C} 2$ & 0.000 & 0.000 & 0.741 & 0.232 & 0.027 \\
\hline C3 & 0.000 & 0.000 & 0.090 & 0.683 & 0.226 \\
\hline $\mathrm{C} 4$ & 0.000 & 0.000 & 0.001 & 0.138 & 0.860 \\
\hline
\end{tabular}

Table 8: Spatial Markov Testo Pooled US-Mexico System 
in each system have transitional dynamics that are conditional upon the geographical context of the region. That is, the transition probability that a region faces is not only a function of the level of income of the region, as is the case in the classic Markov chain framework, but is also sensitive to the income levels of neighboring regions.

Finally, we find evidence that the bi-national border region, composed of a subset of counties from the US and municipios from Mexico, have distribution dynamics that are differentiated from both the internal (i.e., non-border) regions in the U.S. and those in Mexico. Moreover, spatial income mobility is found to be greater for this bi-national group of regions than is the case of regions in either national system. In this sense one can argue that, yes, there is a border economic region for the US-Mexico system.

Our work should be viewed as an initial foray into the spatial distribution dynamics of the US and Mexico. The initial findings clearly raise questions about the possible determinates of mobility differences between the two countries as well as for the border region itself. While those questions ultimately should be addressed with formal econometric methods, we argue that there remains more to do from an exploratory perspective prior to that work. In particular, we plan on revisiting our previous work on interregional inequality dynamics on the Mexican case (Rey and Sastré-Gutiérrez, 2010) by extending it to include a comparative analysis with the US at both the state and county/municipio scales. Doing so will enable us to explore patterns of inequality dynamics, mobility, and growth dynamics from a unified perspective. We expect that inquiry will provide further insights on spatial economic development that can inform subsequent confirmatory work.

\section{References}

Aghion, P., Howitt, P., and García-Peñalosa, C. (1998). Endogenous growth theory. MIT press.

Aghion, P. and Williamson, J. G. (1998). Growth, inequality, and globalization: theory, history, and policy. Cambridge University Press.

Alba, F. (1999). La cuestión regional y la integración internacional de México: una introducción. Estudios Sociológicos, pages 611-631.

Alegría, T. (1989). La ciudad y los procesos transfronterizos entre México y Estados Unidos. Frontera norte, 1(2):53-90.

Amos Jr, O. M. (1988). Unbalanced regional growth and regional income inequality in the latter stages of development. Regional Science and Urban Economics, 18(4):549-566.

Anderson, J. and Gerber, J. (2004). A human development index for the United StatesMexico border. Journal of Borderlands Studies, 19(2):1-26.

Anderson, J. and O'dowd, L. (1999). Borders, border regions and territoriality: contradictory meanings, changing significance. Regional studies, 33(7):593-604. 
Aroca, P., Bosch, M., and Maloney, W. (2005). Spatial dimensions of trade liberalization and economic convergence: México 1985-2002. The World Bank Economic Review, $19(3): 345-378$.

Barro, R. and Sala-i-Martin, X. (1992). Convergence. Journal of Political Economy, $100: 223-251$.

Bickenbach, F. and Bode, E. (2003). Evaluating the markov property in studies of economic convergence. International Regional Science Review, 26(3):363-392.

Blume, L. and Durlauf, S. N. (2001). The interactions-based approach to socioeconomic behavior. Social dynamics, pages 15-44.

Bosker, M. (2009). The spatial evolution of regional GDP disparities in the 'old' and the 'new' Europe. Papers in Regional Science, 88(1):3-27.

Chiquiar, D. (2005). Why Mexico's regional income convergence broke down. Journal of Development Economics, 77(1):257-275.

Costa, S. (2011). Researching Entangled Inequalities in Latin America. The Role of Historical, Social, and Transregional Interdependencies. Ibero-Amerikanisches Institut, Stiftung Preußischer Kulturbesitz.

De Appendini, K. A., Murayama, D., and Domínguez, R. M. (1972). Desarrollo desigual en México, 1900 y 1960. Demografía y economía, 6(1):1-39.

Dobson, S. and Ramlogan, C. (2009). Is there an openness kuznets curve? Kyklos, $62(2): 226-238$.

Durlauf, S. N., Johnson, P. A., and Temple, J. R. (2005). Growth econometrics. Handbook of economic growth, 1:555-677.

Fan, C. C. and Casetti, E. (1994). The spatial and temporal dynamics of US regional income inequality. Annals of Regional Science, 28:177-196.

Fan, S., Kanbur, R., Zhang, X., et al. (2009). Regional inequality in China: trends, explanations and policy responses. Routledge.

Fingleton, B. (1997). Specification and testing of Markov chain models: an application to convergence in the European Union. Oxford Bulletin of Economics and Statistics, 59(3):385-403.

Graizbord, B. and Hiernaux, D. (1982). Algunas consideraciones geográficas para el análisis del espacio fronterizo. In Memorias del primer encuentro sobre impactos regionales de las relaciones económicas México-Estados Unidos, number [s.n.]. in Tomo III, pages 671-697.

Hernández Laos, E. (1984). La desigualdad regional en México (1900-1980). In Cordera, R. and Tello, C., editors, La desigualdad en México, pages 155-192. Siglo XXI Editores. 
Herzog, L. A. (1990). Where north meets south: cities, space, and politics on the USMexico border. University of Texas Press.

Hughes, R. B. (1961). Interregional income differences: Self-perpetuation. Southern Economic Journal, pages 41-45.

Jessop, B., Brenner, N., Jones, M., et al. (2008). Theorizing sociospatial relations. Environment and planning. D, Society and space, 26(3):389.

Kanbur, R. and Zhang, X. (2005). Fifty years of regional inequality in China: a journey through central planning, reform, and openness. Review of development Economics, $9(1): 87-106$.

Kanbur, S. and Venables, A. (2005). Spatial inequality and development. Oxford University Press, USA.

Krebs, G. (1982). Regional inequalities during the process of national economic development: a critical approach. Geoforum, 13(2):71-81.

Krugman, P. (1990). Increasing returns and economic geography. Technical report, National Bureau of Economic Research.

Krugman, P. (1997). Development, geography, and economic theory, volume 6. The MIT Press.

Krugman, P. (1999). The role of geography in development. International Regional Science Review, 22(2):142-161.

Krugman, P. (2004). The 'new'economic geography: Where are we? Unpublished manuscript. Department of Economics, Princeton University, pages 1-14.

Krugman, P. and Hanson, G. (1993). Mexico-US free trade and the location of production. The Mexico-US Free Trade Agreement, PM Mark (ed.), pages 163-168.

Krugman, P. and Venables, A. J. (1995). Globalization and the inequality of nations. The Quarterly Journal of Economics, 110(4):857-880.

Kuznets, S. (1955). Economic growth and income inequality. The American Economic Review, pages 1-28.

Le Gallo, J. (2004). Space-time analysis of GDP disparities among European regions: A Markov chains approach. International Regional Science Review, 27(2):138-163.

Li, Y. and Wei, Y. (2010). The spatial-temporal hierarchy of regional inequality of China. Applied Geography, 30(3):303-316.

Lobao, L., Hooks, G., and Tickamyer, A. (2008). Poverty and inequality across space: sociological reflections on the missing-middle subnational scale*. Cambridge Journal of Regions, Economy and Society, 1(1):89-113. 
Lobao, L., Hooks, G., and Tickamyer, A. R. (2007a). Advancing the sociology of spatial inequality. The sociology of spatial inequality, pages 1-28.

Lobao, L. M., Hooks, G., and Tickamyer, A. R. (2007b). The sociology of spatial inequality. SUNY Press.

López-Alonso, M. (2007). Growth with Inequality: Living Standards in Mexico, 18501950. Journal of Latin American Studies, 39(01):81-105.

López-Bazo, E., Vayá, E., Mora, A. J., and Surinach, J. (1999). Regional economic dynamics and convergence in the European Union. The Annals of Regional Science, $33(3): 343-370$.

Lorey, D. E. and Buj, L. (1991). El surgimiento de la región fronteriza entre Estados Unidos y México en el siglo XX. Revista Mexicana de Sociología, pages 305-347.

Magrini, S. (2007). Analysing convergence through the distribution dynamics approach: why and how? University Ca'Foscari of Venice, Dept. of Economics Research Paper Series No, 13.

Maxwell, P. (1994). Trends in regional income disparities: an Australian perspective on the Canadian experience. Canadian Journal of Regional Science, 17(2):189-215.

Mendoza Cota, J. E. (2006). La integración económica de las ciudades de la frontera México-Estados Unidos. Análisis Económico, 21(46):307-325.

Messmacher, M. (2000). Desigualdad regional en México. El efecto del TLCAN y otras reformas estructurales. Documento de investigación. Dirección General de Investigación Económica, Banco de México.

Mollá Ruiz-Gómez, M. (2011). La región fronteriza México-Estados Unidos, un lugar de unión y desencuentros. Investigaciones Geográficas, 55:169-180.

Newman, D. (2006). The lines that continue to separate us: borders in our borderless' world. Progress in Human Geography, 30(2):143-161.

Niebuhr, A. (2006). Spatial effects of european integration: Do border regions benefit above average?(symposium article). The Review of Regional Studies, 36(3):254-278.

Niebuhr, A. and Stiller, S. (2002). Integration effects in border regions: a survey of economic theory and empirical studies. Technical report, HWWA discussion paper.

Novotnỳ, J. (2007). On the measurement of regional inequality: does spatial dimension of income inequality matter? The Annals of Regional Science, 41(3):563-580.

Ohr, R. (1995). Divergence or convergence as a consequence of regional integration?NAFTA's Impacts on Mexico. In International economic integration, pages 245-263. Springer. 
Ordóñez, B. G. (2013). Condiciones de marginalidad y principales retos sociales en la franja fronteriza del norte de México. Asian Journal of Latin American Studies, 26(2):89-102.

Pick, J. B., Viswanathan, N., and Hettrick, J. (2002). The US-Mexican borderlands region: a binational spatial analysis. The Social Science Journal, 38(4):567-595.

Prais, S. J. (1955). Measuring social mobility. Journal of the Royal Statistical Society Series A, 118:56-66.

Pries, L. (2005). Configurations of geographic and societal spaces: a sociological proposal between 'methodological nationalism'and the 'spaces of flows'. Global Networks, 5(2):167-190.

Quah, D. (1993a). Empirical cross-section dynamics in economic growth. European Economic Review, 37(2-3):426-434.

Quah, D. (1993b). Galton's fallacy and tests of the convergence hypothesis. The Scandinavian Journal of Economics, 95(4):427-443.

Quah, D. (1996a). Regional convergence clusters across Europe. European Economic Review, 40(3):951-958.

Quah, D. (2001). Searching for prosperity a comment. In Carnegie-Rochester Conference Series on Public Policy, volume 55, pages 305-319. Elsevier.

Quah, D. (2003). One third of the world's growth and inequality. Inequality and Growth: Theory and Policy Implications, 1:27.

Quah, D. T. (1996b). Empirics for economic growth and convergence. European Economic Review, 40(6):1353-1375.

Quah, D. T. (1996c). Twin peaks: growth and convergence in models of distribution dynamics. The Economic Journal, pages 1045-1055.

Rey, S. J. (2001). Spatial empirics for economic growth and convergence. Geographical Analysis, 33(3):195-214.

Rey, S. J. (2004a). Spatial analysis of regional income inequality. In Goodchild, M. and Janelle, D., editors, Spatially Integrated Social Science: Examples in Best Practice, pages 280-299. Oxford University Press.

Rey, S. J. (2004b). Spatial dependence in the evolution of regional income distributions. In Getis, A., Múr, J., and Zoeller, H., editors, Spatial Econometrics and Spatial Statistics. Palgrave, Hampshire.

Rey, S. J. (2014a). Discrete regional distributional dynamics revisited. Regional and Urban Economics. Forthcoming.

Rey, S. J. (2014b). Fast algorithms for a space-time concordance measure. Computational Statistics, 29(3-4):799-811. 
Rey, S. J. (2014c). Rank-based markov chains for regional income distribution dynamics. Journal of Geographical Systems, 16(2):115-137.

Rey, S. J. and Janikas, M. (2005). Regional convergence, inequality, and space. Journal of Economic Geography, 5(2):155-176.

Rey, S. J. and Janikas, M. (2006). STARS: space-time analysis of regional systems. Geographical Analysis, 38(1):67-86.

Rey, S. J., Murray, A., and Anselin, L. (2011). Visualizing regional income distribution dynamics. Letters in Spatial and Resource Sciences, 4(1):81-90.

Rey, S. J. and Sastré-Gutiérrez, M. L. (2010). Interregional Inequality Dynamics in Mexico. Spatial Economic Analysis, 5(3):277-298.

Sánchez-Reaza, J. and Rodríguez-Pose, A. (2002). The impact of trade liberalization on regional disparities in Mexico. Growth and change, 33(1):72-90.

Sastré-Gutiérrez, M. and Rey, S. (2013). Space-Time Income Distribution Dynamics in Mexico. Annals of GIS, Forthcoming.

Scott, A. J. and Storper, M. (2007). Regions, globalization, development. Regional studies, 41(S1):S191-S205.

SEMARNAT (1983). Convenio entre los Estados Unidos Mexicanos y los Estados Unidos de América sobre la Cooperación para la protección y mejoramiento del medio ambiente en la zona fronteriza. Technical report, Secretaría del Medio Ambiente y Recursos Naturales.

Shorrocks, A. (1978). The measurement of mobility. Econometrica: Journal of the Econometric Society, pages 1013-1024.

Silva, J. A. and Leichenko, R. M. (2004). Regional income inequality and international trade. Economic Geography, 80(3):261-286.

Venables, A. J. (2005). Spatial disparities in developing countries: cities, regions, and international trade. Journal of Economic Geography, 5(1):3-21.

Wan, G., Lu, M., and Chen, Z. (2007). Globalization and regional income inequality: empirical evidence from within China. Review of Income and Wealth, 53(1):35-59.

Wei, Y. D. (2002). Multiscale and multimechanisms of regional inequality in China: implications for regional policy. Journal of Contemporary China, 11(30):109-124.

Wei, Y. D. and Ye, X. (2009). Beyond convergence: Space, scale, and regional inequality in China. Tijdschrift voor Economische en Sociale Geografie, 100(1):59-80.

Williamson, J. G. (1965). Regional inequality and the process of national development: a description of the patterns. Economic development and cultural change, pages 1-84. 
Wilson, T. M. and Donnan, H. (1998). Border identities: nation and state at international frontiers. Cambridge University Press.

Yamamoto, D. (2007). Scales of regional income disparities in the USA, 1955-2003. Journal of Economic Geography, 8:79-103.

Zhang, X. and Zhang, K. H. (2003). How does globalisation affect regional inequality within a developing country? evidence from china. Journal of Development Studies, 39(4):47-67. 